\title{
Analiza możliwości kruchego pękania spawanych elementów konstrukcji stalowych
}

\author{
The analysis of the possibility of fragile cracking \\ steel units of welded constructions
}

\section{Streszczenie}

W pracy przedstawiono ocenę zniszczenia stalowych złączy spawanych w wyniku kruchego pękania. Wykazano, że krytyczne wartości odporności na pękanie i rozwarcia czoła pęknięcia mogą być wyznaczone na podstawie wyników badania udarności. Dokonano wstępnej oceny dopuszczalnej długości szczelin (niezgodności spawalniczych) w tych złączach ze względu na możliwość kruchego pękania.

Słowa kluczowe: złącza spawane, kruche pękanie, niezgodności złączy spawanych
Abstract

In the work the opinion of possible destruction of steel welded joints in the result of fragile cracking was introduced. Show, that the critical values of the resistance on cracking and the crack tip opening displacement can be appointed on basis of the test results of the impact resistance. The preliminary opinion of the admissible length of fissures (welded joints' incompatibilities) was executed in these joints because of the possibility of fragile cracking.

Keywords: welded joins, fragile cracking, welded joints' incompatibilities

\section{Wstęp}

Stale konstrukcyjne i złącza spawane poddane działaniu obciążenia rozciągającego narażone są nagłe kruche pękanie. Niebezpieczeństwo takie występuje w przypadku istnienia w złączu koncentratora spiętrzającego poziom naprężenia [1]. Takim koncentratorem może być karb geometryczny, tj. szczelina powierzchniowa lub wewnętrzna, otwór, skokowa zmiana wymiarów przekroju, albo nieciągłość materiału, np.: wtrącenie niemetaliczne, pęcherz powietrzny itp. Ponadto koncentrację naprężenia powodują też zmiany struktury materiału i kształtu elementu generujące w nim naprężenia własne [2]. Złącza spawane zawierają zwykle wszystkie wymienione rodzaje koncentratorów. Są to niezgodności spawalnicze takie jak: braki przetopu, pęcherze, wtrącenia obce w spoinie, pęknięcia wskrośne, odkryte i ukryte oraz różne struktury: materiału rodzimego, strefy wpływu ciepła (SWC) i spoiny. Istniejące wady i niezgodności w złączach spawanych mogą prowadzić do zniszczenia elementów szczególnie przy obciążeniach zmęczeniowych [3,4]

Pękanie kruche charakterystyczne dla materiałów kruchych (np. dla żeliwa) występuje także w materiałach sprężysto-plastycznych jakimi są stale, jeżeli panuje w nich płaski stan naprężenia (PSO) lub stan zbliżony do niego. Stan taki istnieje w elementach o dużej grubości przy niewielkich rozmiarach wady (szczeliny) w porównaniu z wymiarem elementu w kierunku wzrostu pęknięcia $[5,6]$. Kruchość stali wzrasta szczególnie znacząco w niskich temperaturach pracy rzędu $-40{ }^{\circ} \mathrm{C}$ i niższych. W takich warunkach strefa plastyczna na czole szczeliny jest bardzo mała w porównaniu z jej wielkością i występuje tylko w cienkich warstwach powierzchniowych danego elementu. Można wtedy stosować jednoparametrowe kryterium siłowe liniowo-sprężystej mechaniki pękania (LSMP). Pękanie kruche wystąpi gdy współczynnik intensywności naprężenia $K I$ na czole szczeliny osiągnie wartość krytyczną Klc (wyznaczaną doświadczalnie), zwaną odpornością na pękanie $[5,7]$,

$$
K_{l}=\sigma \sqrt{\pi a}=K_{l c}
$$

W przypadku większej strefy odkształceń plastycznych na czole szczeliny, sięgającej głębszych warstw elementu stosuje się dwuparametrowe kryterium deformacyjne sprężysto-plastycznej mechaniki pękania (SPMP) [8]. Kryterium to dotyczy quasi-kruchego stanu materiału. Warunkiem pękania jest osiągnięcie w wyniku odkształceń plastycznych rozwarcia czoła szczeliny $\delta_{a}=2 v_{a}$ równego jego wartości krytycznej $\delta_{c}$ przy obciążeniu $S r=\sigma / R_{e} \leq 0,8$ :

$$
\delta_{a}=\delta_{c}
$$

Przy bardzo dużych odkształceniach na czole pęknięcia stosowane jest podobne kryterium pękania $\left(J=J_{c}\right)$ określające energię potrzebną do nagłej propagacji pęknięcia - całkę J.

Dla szybkiej oceny połączeń spawanych na możliwość nagłego pękania przy założeniu istnienia $w$ nich niezgodności spawalniczych można skorzystać z obu kryteriów (1) i (2), a zwłaszcza z kryterium LSMP, które pozwala na określenie rzeczywistej krytycznej wielkości ac wady (szczeliny)

Dr hab. inż. Krzysztof Werner, Prof. PCz; dr inż. adiunkt Kwiryn Wojsyk - Politechnika Częstochowska. Autor korespondencyjny/Corresponding author. krzysztofwerner@tlen.pl 
przy poziomie nominalnego naprężenia rozciągającego $\sigma$ do granicy plastyczności $R_{e}$ spełniającym warunek $\sigma / R_{e}<0,5$. Kryterium to można stosować też w zakresie SPMP, zamiast kryterium (2), przy założeniu, że $\sigma / R_{e}<0,8$. Wtedy krytyczną wielkość szczeliny $a_{c}$ określa się dla efektywnego wymiaru wady $a_{\text {eff }}$ tj. rzeczywistego wymiaru szczeliny - a powiększonego o zasięg strefy plastycznej na jej czole $-r_{p}\left(a_{e f}=a+r_{p}\right)$. Procedury wyznaczenia wielkości krytycznych $K_{c c}, \delta_{c}, J_{c}$, określających odporność materiału na pękanie, są trudne do realizacji w warunkach przemysłowych, ponieważ wymagają specjalistycznych stanowisk laboratoryjnych oraz spełnienia ostrych warunków wykonania i badania próbek $[7,8]$.

W niniejszej pracy okręślono wielkości krytyczne $K_{l c}$ i $\delta_{c}$ na podstawie wyników badań udarności KCV - powszechnie stosowanych dla złączach spawanych (elementów konstrukcji spawanych) oraz przedstawiono proste metody wyznaczenia wielkości dopuszczalnych wad.

\section{Wyniki badań udarności i wyznaczenie parametrów odporności na pękanie}

Badania udarności przeprowadzono dla złączy spawanych doczołowo (w pozycji PF) metodą 135 MAG ze spoiną typu "V" i "1/2V". Złącza wykonano z blach stali o podwyższonej wytrzymałości S355J2+N w stanie po normalizacji o grubości $12 \mathrm{~mm}$ [9]. Granica plastyczności tej stali wynosiła $R_{e}=384 \mathrm{MPa}$, a wytrzymałość na rozciąganie $R_{m}=574 \mathrm{MPa}$. Drut spawalniczy G3Si1 $(d=1,2 \mathrm{~mm})$ miał $R_{e}=450 \mathrm{MPa}$ i $R_{m}=545 \mathrm{MPa}$.

a)

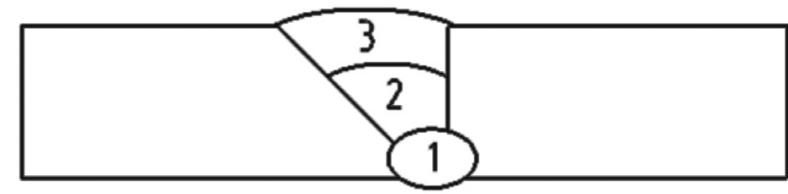

b)

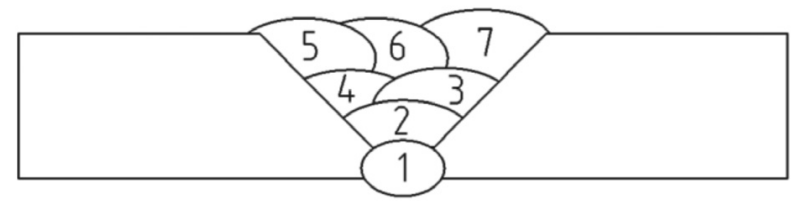

Rys. 1. Schemat wykonywanych ściegów w spoinie typu: V (a) i 1/2V (b) Fig. 1. The scheme of executed welding sequences in the joint of the type: $V(a)$ i $1 / 2 V(b)$

Udarność złączy badano w temperaturach: $+25,-25 \mathrm{i}-75^{\circ} \mathrm{C}$ zgodnie z normami [10-12] na próbkach o przekroju w karbie 10x8 mm pobranych w różnej odległości I od osi spoiny. Na podstawie wyników badań pracy udarowego zginania $K V$ (wyrażonej w J) określono wielkość krytycznego rozwarcia czoła pęknięcia $\delta_{c}$ wg wzoru (3) (podanego w pracy [8], skorygowanego przez autorów tego artykułu) oraz odporność na pękanie $K_{\text {Ic }}$ (wz. 4) [6,8] w różnych strefach złączy (tabl. I).

$$
\begin{gathered}
\delta_{c}=0,0024 \cdot(K V) \\
K_{l}=\sqrt{R_{e} \cdot \delta \cdot E}
\end{gathered}
$$

Wyniki badań $\mathrm{w}$ temp. $\mathrm{t}=-25^{\circ} \mathrm{C}$ wskazują na znacznie mniejszą udarność spoiny i SWC w porównaniu do udarności materiału rodzimego. W temperaturze $-75^{\circ} \mathrm{C}$ udarność w spoinie była bardzo niska, natomiast w SWC była wysoka (wyższa niż w materiale rodzimym). Odporności na pękanie (tabl. I) obliczone ze wzoru (4) na podstawie rozwarcia pęknięcia opisanego zależnością (3) były prawie identyczne jak wyznaczone ze wzoru (5) na podstawie wartości KV (wyrażonej w J) [8].

$$
K_{l}=14,5 \sqrt{(K V)}
$$

\section{Ocena dopuszczalnej wielkości wady ze względu na kruche pękanie}

Dopuszczalne długości $a=a_{d}$ centralnej szczeliny wskrośnej $\left(2 a_{d}\right)$ w płaskiej tarczy o szerokości w obliczono przy współczynniku bezpieczeństwa $b=2 \mathrm{w}$ oparciu o uproszczoną wersję kryterium LSMP wg pierwszego poziomu oceny [8] dla obciążenia $S_{r}=0,8$ przy założonych wartościach w/a we współczynniku korekcyjnym $\mathrm{Y}$.

$$
\begin{gathered}
\left.K_{l} \mid K_{2}=K_{r}=1 / \sqrt{2} \text { obowiązującego dla } S_{r}=\sigma / \sigma_{f} \leq 0,8 \quad 6\right) \\
\text { gdzie } \quad \begin{array}{c}
K_{l}=\sigma \sqrt{\pi \cdot a} \cdot \gamma=\sigma \sqrt{\pi \cdot a} \cdot \sqrt{\frac{w}{\pi \cdot a} \operatorname{tg} \frac{\pi \cdot a}{W},} \\
\sigma_{f}=0,5 \cdot\left(R_{e}+R_{m}\right) \leq 1,2 \cdot R_{e}
\end{array}
\end{gathered}
$$

Ponadto dopuszczalne wartości takiej szczeliny wyznaczono z doświadczalnej zależności (7) dla założonych szerokości w płyty (złącza):

$$
a_{d}=0,5 \cdot\left(\mathrm{p}-\sqrt{\mathrm{p}^{2}-5 w \cdot(\mathrm{KCV}) \cdot\left(1-R_{e} / R_{m}\right)}\right)
$$

gdzie

$$
p=w+1,25 \cdot(\mathrm{KCV})
$$

Określono także wielkość dopuszczalną $a_{m}$ równoważnej centralnej wady wskrośnej $\left(2 a_{m}\right)$ wg najprostszych kryteriów LSMP (wz. 8) [8] i SPMP (wz. 9) [7]:

$$
\begin{gathered}
a_{m}=\mathrm{C}\left(\mathrm{K}_{\mathrm{ic}} / R_{e}\right)^{2}, \\
a_{m}=\mathrm{C}\left(\delta_{c} /\left(R_{e} / E\right)\right),
\end{gathered}
$$

gdzie

$$
\mathrm{C}=\frac{1}{2 \pi\left(\left(\sigma / R_{e}\right)-0,25\right)} \quad \text { dla } \sigma / R_{e} \geq 0,5
$$

$\mathrm{Na}$ podstawie wielkości dopuszczalnej $a_{m}$ równoważnej centralnej wady wskrośnej można wyznaczyć dopuszczalną długość 2c szczeliny powierzchniowej (odkrytej) lub szczeliny wewnętrznej (ukrytej) dla wymiaru a takiej szczeliny równego wartości $a_{m}\left(a=a_{m}\right)$. Do tego celu można wykorzystać bardzo skomplikowany tok obliczeń przedstawiony w pracach $[6,8]$ albo znacznie prostszy sposób - na podstawie wykresów korelacyjnych, tj. korelacji wymiarów tych pęknięć z wartością $a_{m}$ wskrośnego pęknięcia równoważnego, przedstawionych w pracy [7].

Wyniki obliczeń długości wskrośnej szczeliny dopuszczalnej w badanych strefach złącza dla $S_{r}=0,8$ przedstawiono

Tablica I. Wyniki badań udarności i obliczeń rozwarcia czoła pęknięcia i odporności na pękanie

Table I. The results of investigations of the impact resistance and the calculations of the crack tip opening displacement and resistance on cracking

\begin{tabular}{|c|c|c|c|c|c|c|}
\hline \multirow{2}{*}{$\begin{array}{c}\text { Strefa złącza spawnego } \\
(1, \mathrm{~mm})\end{array}$} & \multicolumn{3}{|c|}{ Złącze V, $\mathrm{t}=-25^{\circ} \mathrm{C}$} & \multicolumn{3}{c|}{ Złącze $1 / 2 \mathrm{~V}, \mathrm{t}=-75^{\circ} \mathrm{C}$} \\
\cline { 2 - 8 } & $\mathrm{KV}$ & $\begin{array}{c}\delta_{c,}(\mathrm{wz} .3) \\
\mathrm{mm}\end{array}$ & $\begin{array}{c}K_{c,}(\mathrm{wz} .4) \\
\mathrm{MPa} \cdot \mathrm{m}^{0,5}\end{array}$ & $\begin{array}{c}\mathrm{KV} \\
\mathrm{J}\end{array}$ & $\begin{array}{c}\delta_{c}(\mathrm{wz} .3) \\
\mathrm{mm}\end{array}$ & $\begin{array}{c}K_{c,}(\mathrm{wz} .4) \\
\mathrm{MPa} \cdot \mathrm{m}^{0,5}\end{array}$ \\
\hline Spoina (0) & 124 & 0,308 & 159,49 & 9 & 0,021 & 41,19 \\
\hline SWC (5,5) & 134 & 0,333 & 165,80 & 208 & 0,475 & 198,00 \\
\hline Mat.rodz. (17,5) & 213 & 0,514 & 206,02 & 143 & 0,326 & 164,17 \\
\hline
\end{tabular}


na rysunkach $2 \div 5$. Na rysunku 2 dla $t=-25^{\circ} \mathrm{C}$ widoczne są bardzo różne wartości dopuszczalnej długości szczeliny wskrośnej dla różnych odległości od osi spoiny. W odległości $l=0-5,5 \mathrm{~mm}$ wartości $a_{d}$ są dużo mniejsze niż dla $/>5,5$ $\mathrm{mm}$. Można to tłumaczyć działaniem własnych naprężeń rozciągających w spoinie i jej SWC. Obliczenie długości $a_{d}$ wg wzoru (6) dało zbliżone wyniki do równoważnej długości pęknięcia $a_{m}$, wyznaczonej ze wzoru (8) lub (9) z uwzględnieniem naprężeń własnych w spoinie i w SWC (przyjętych na poziomie $R_{e}$ ) tylko przy małym stosunku szerokości próbki do długości pęknięcia (w/a).

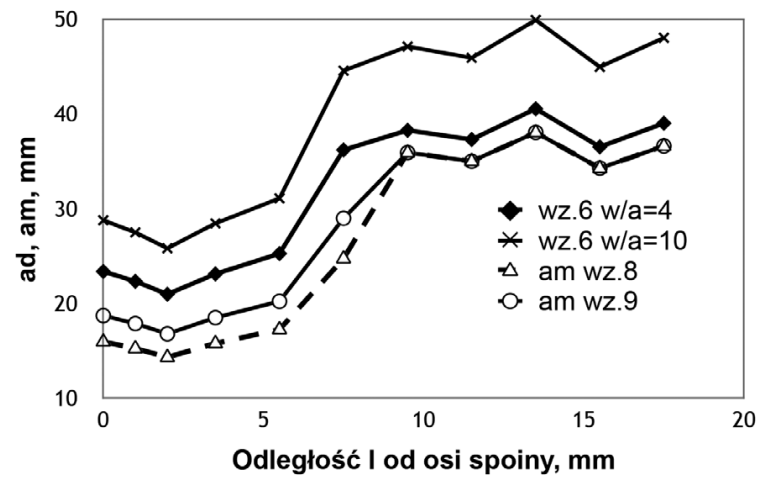

Rys. 2. Długość wskrośnej szczeliny dopuszczalnej i równoważnej dla $t=-25^{\circ} \mathrm{C}$

Fig. 2. The length of the admissible and equivalent thoroughly fissure for $t=-25^{\circ} \mathrm{C}$

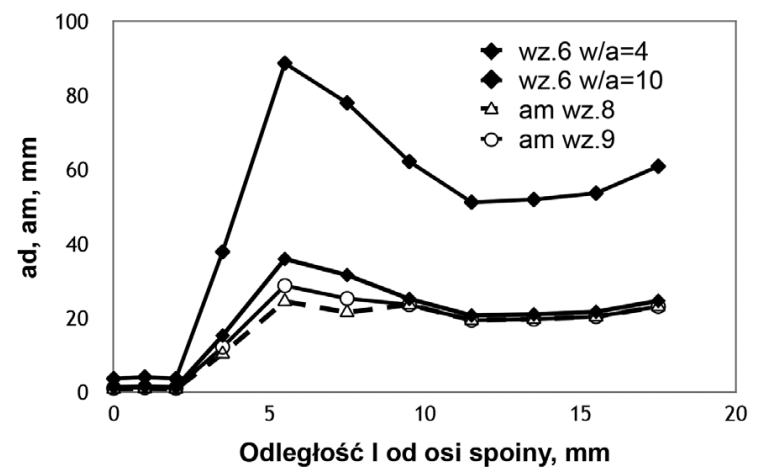

Rys. 3. Długość wskrośnej szczeliny dopuszczalnej i równoważnej dla $t=-75^{\circ} \mathrm{C}$

Fig. 3. The length of the admissible and equivalent thoroughly fissure for $t=-75^{\circ} \mathrm{C}$
Podobny charakter zmian, chociaż jeszcze bardziej zróżnicowany wystąpił dla temp. $\mathrm{t}=-75^{\circ} \mathrm{C}$, (rys. 3), ale wyniki obliczeń bezpiecznej i równoważnej długości pęknięć w spoinie, w SWC i w materiale rodzimym według wzorów (8) i (9) oraz ( 6 dla $w / a=4)$ były prawie takie same.

Przy zastosowaniu wzoru (7) charakter zmian wartości $a_{d}$ jest podobny do ad obliczonych wg wzoru (6) ale wartości $a_{d}$ obliczone $z$ tego wzoru są nieco niższe niż ze wzoru (6) zarówno dla $\mathrm{t}=-25^{\circ} \mathrm{C}$ (rys. 4), jak i dla $t=-75^{\circ} \mathrm{C}$ (rys. 5).

Długości dopuszczalnych szczelin przy niższym poziomie naprężenia (np. Sr=0,5) mogą być znacznie większe.

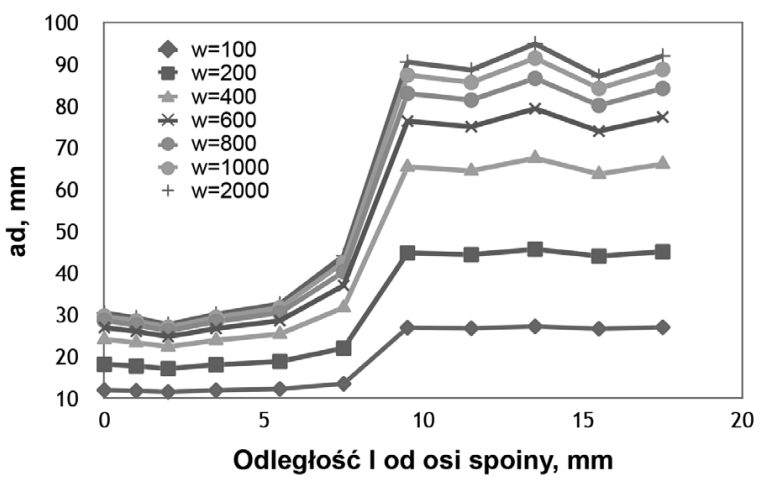

Rys. 4. Długość wskrośnej szczeliny dopuszczalnej (wz.7) w złączu spawanym o różnej szerokość $\mathrm{w}(\mathrm{w} \mathrm{mm})$ dla $t=-25^{\circ} \mathrm{C}$

Fig. 4. The length of the admissible thoroughly fissure (formula 7) in weld joint about various the width $\mathrm{w}$ (in $\mathrm{mm}$ ) for $t=-25^{\circ} \mathrm{C}$

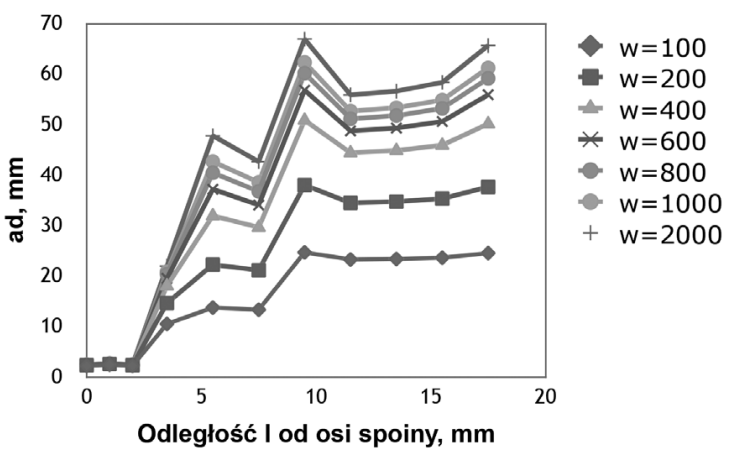

Rys. 5. Długość wskrośnej szczeliny dopuszczalnej (wz.7) w złączu spawanym o różnej szerokość $\mathrm{w}(\mathrm{w} \mathrm{mm})$ dla $t=-75^{\circ} \mathrm{C}$

Fig. 5. The length of the admissible thoroughly fissure (formula 7) in weld joint about various the width $\mathrm{w}$ (in $\mathrm{mm}$ ) for $t=-75^{\circ} \mathrm{C}$

\section{Podsumowanie}

Przeprowadzone badania złączy spawanych wykazały:

Istnieje możliwość wyznaczania parametrów charakteryzujących odporność materiału na pękanie na podstawie badań udarności.

Zastosowanie uproszczonych kryteriów pękania kruchego i quasi-kruchego z wykorzystaniem wyznaczonych parametrów odporności na pękanie pozwala określić dopuszczalną wielkość wad materiałowych i niezgodności spawalniczych.

Uzyskane dane potwierdziły przydatność zastosowanej metodyki obliczania wielkości wad i niezgodności w zakresie pracy konstrukcji stalowych, tj. w temperaturach do $t=-75^{\circ} \mathrm{C}$.

\section{Literatura}

[1] Gwóźdź M., Michałowski T.: Elementy niezawodności stalowych spawanych zbiorników na ciecze i gazy płynne. Przegląd Spawalnictwa 3/2012 s. 3-10.

[2] Prażmowski M., Rozumek D.: Rozwój pęknięć przy cyklicznym zginaniu w złączu cyrkon-stal powstałych w wyniku zgrzewania wybuchowego. Przegląd Spawalnictwa 4/2014 s. 45-50.

[3] Stasiuk P., Karolczuk A., Kuczko W.: Rozkład naprężeń w krzyżowym złączu spawanym z uwzględnieniem rzeczywistego kształtu spoiny. Przegląd Spawalnictwa 1/2014 s. 29-33.

[4] Kukla D., Grzywna P., Karczewski R.: Ocena rozwoju uszkodzenia zmęczeniowego na podstawie zmian i parametrów prądowirowych w kolejnych cyklach obciążenia. Przegląd Spawalnictwa 5/2014 s. 23-3.1

[5] Kocańda S.: Zmęczeniowe pękanie metali, WNT Warszawa 198.

[6] Neimitz A.: Mechanika pękania, PWN Warszawa 1998.
[7] Brózda J.: Wprowadzenie do mechaniki pękania, Instytut Spawalnictwa Gliwice 2008.

[8] Rykaluk K.: Pęknięcia w konstrukcjach stalowych, Dolnośląskie Wydawnictwo Edukacyjne Wrocław 2000.

[9] Miśta J. Określanie wielkości niezgodności spawalniczych w oparciu o kryteria mechaniki pękania. Praca magisterska pod kier. K. Wojsyka, Częstochowa 2013

[10] PN-EN 875: Spawalnictwo - Badania niszczące spawanych złączy metali - Próba udarności - Usytuowanie próbek, kierunek karbu i badanie.

[11] PN-EN ISO 10045-1: Metale. Próba udarności sposobem Charpy'ego. Metoda badania.

[12] PN-EN ISO 14556: Stal. Próba udarności Charpy-V oprzyrządowanym młotem wahadłowym. Metoda badania. 